\title{
Malrotation in patients with duodenal atresia: a true association or an expected finding on postoperative upper gastrointestinal barium study?
}

\author{
J.M.Zerin ${ }^{1}$, T.Z.Polley Jr ${ }^{2}$ \\ ${ }^{1}$ Department of Radiology, Riley Hospital for Children, Indiana University Medical Center, 702 Barnhill Drive, Indianapolis, \\ IN 46202-2920, USA \\ ${ }^{2}$ Department of Surgery, Division of Pediatric Surgery, University of Michigan Hospitals, Ann Arbor, MI 48109-0252, USA
}

Received: 15 November 1993/Accepted: 24 January 1994

\begin{abstract}
We retrospectively reviewed the imaging and surgical findings in 17 patients with duodenal atresia to determine (a) the frequency of coexistent malrotation in patients with duodenal atresia and (b) the reliability of the upper gastrointestinal barium study (UGI) in differentiating malrotation from postoperative deformity of the duodenal sweep after repair of duodenal atresia. Postoperatively, $9(53 \%)$ of the 17 patients had UGI findings consistent with malrotation. Of these nine, only two had malrotation coexistent with duodenal atresia, while the other seven had normal midgut rotation demonstrated intraoperatively. The radiographic appearance of malrotation was simulated in two patients in whom the ligament of Treitz had been surgically divided, in three in whom the ligament had not been taken down, and in two in whom the status of the ligament was not specified in the surgical report. Although there is an association between duodenal atresia and malrotation, this cannot be accurately documented on postoperative UGI examination. Malrotation cannot be detected preoperatively because contrast material cannot pass beyond the level of the atresia. Postoperatively, surgical deformity of the duodenal sweep cannot be reliably distinguished from malrotation.
\end{abstract}

Malrotation of the midgut reportedly occurs in 8-34 \% of patients with duodenal atresia [1-4]. However, when there is atresia of the proximal duodenum the radiologist is unable to completely evaluate the duodeno-jejunal flexure during preoperative upper gastrointestinal barium study (UGI) because the contrast material cannot get through. Conversely, postoperative displacement and deformity of the duodenal sweep and proximal jejunum can mimic the appearance of malrotation following repair of duodenal atresia. We retrospectively reviewed the imaging and surgical findings in a group of patients

Correspondence to: J.M.Zerin with duodenal atresia to determine the frequency of coexistent malrotation in patients with duodenal atresia and the reliability of UGI in differentiating malrotation from postoperative deformity of the duodenal sweep after repair of duodenal atresia.

\section{Materials and methods}

We used a computerized data base of pediatric surgical patients to retrospectively identify 35 children ( 23 girls, 12 boys) who underwent operation at our hospital during the neonatal period (median age 1 day) for duodenal atresia over a 17 -year period. We reviewed the patients' medical records, including the operative report, and recorded the following information in each case: (a) whether the mesentery of the midgut was normal or abnormal and if malrotation of the midgut was present at operation, (b) whether the ligament of Treitz was mobilized during the repair, and (c) whether any other gastrointestinal anomalies were present. Seventeen (49\%) of the 35 patients underwent postoperative UGI in our hospital. An experienced pediatric radiologist (J.M.Z.), who was blind to the operative findings, reviewed each UGI using conventional criteria [5-7] for the diagnosis of malrotation. We then compared the postoperative radiological findings with the surgical diagnoses and procedures.

\section{Results}

Thirty-four patients had duodeno-duodenostomy and one had duodeno-jejunostomy. Four $(11 \%)$ of the 35 patients had abnormal mesenteric fixation with malrotation of the midgut diagnosed during surgical repair of duodenal atresia. Ladd procedure was performed in each of these four patients. Two of them also had postoperative UGI and in both of these patients the course and position of the duodeno-jejunal flexure were abnormal and consistent with the typical appearance seen in cases of malrotation (Fig.1). However, seven other patients who had normal mesenteric fixation demonstrated intraoperatively also had a postoperative radiographic appearance simulating malrotation (Fig. 2). In two of these seven patients the ligament of Treitz had been surgically divided, in three the ligament had not been di- 

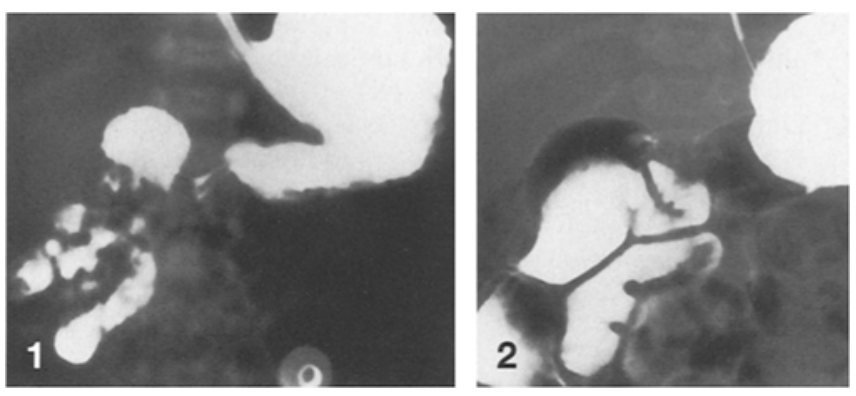

Fig. 1. A newborn boy presented with bilious vomiting and abdominal distension. Abdominal radiographs showed a "doublebubble" appearance with no bowel gas distally, typical of duodenal atresia. At the age of 1 day, upper gastrointestinal barium study (UGI) showed that no barium or gas had passed beyond the proximal duodenum. Duodenal atresia with annular pancreas was found at operation, and duodeno-duodenostomy was performed. Malrotation (without volvulus) was also diagnosed and several Ladd bands were lysed. At postoperative UGI, the duodenum and proximal jejunum were noted to descend completely to the right of the spine, consistent with malrotation

Fig. 2. A girl with Down syndrome and duodenal atresia underwent duodeno-duodenostomy at 2 days of age. Postoperatively, her abdomen remained distended and she continued to vomit. Rectal biopsy was diagnostic of Hirschsprung's disease and she underwent endorectal pull-through. At 7 months of age she again presented with bilious vomiting. At UGI the duodenum and proximal jejunum were dilated and to the right of the midline suggesting malrotation. However, her pediatric surgeon had clearly documented that midgut position and mesentery were normal when he operated on her for duodenal atresia

vided, and in two the status of the ligament was not specified in the surgical report. The sensitivity of postoperative UGI in detecting coexistent malrotation was 1.00. However, the specificity of the postoperative UGI for malrotation was only 0.29 and the overall accuracy was 0.71 .

Seven $(20 \%)$ of the 35 children had additional gastrointestinal anomalies apart from duodenal atresia and malrotation and all underwent postoperative UGI. Five of the seven had coexistent esophageal atresia, and postoperative UGI findings suggested that four of these had malrotation, although this was only confirmed in one child at operation. One child with Hirschsprung's disease also had a radiographic appearance very suggestive of malrotation, but had normal mesenteric fixation demonstrated intraoperatively (Fig. 2). One child with biliary atresia had normal postoperative UGI and no evidence of malrotation at operation.

\section{Discussion}

Malrotation and duodenal atresia are among the most frequent causes of bilious vomiting in the neonate [1]. The typical radiographic appearance of a "double bubble" with no gas distal to the duodenum is diagnostic of complete or near-complete duodenal obstruction, most commonly duodenal atresia. Contrast studies of the gastrointestinal tract are usually not required to diagnose duodenal atresia [8-9]. However, malrotation of the midgut occasionally coexists with duodenal atresia [1-4] (as was the case in $11 \%$ of our patients). It is impossible to detect such malrotation preoperatively at UGI because contrast material cannot pass beyond the level of the atresia [9]. This limitation of UGI is a source of concern in managing these delicate patients because the presence of malrotation indicates more urgent repair than does duodenal atresia alone [1].

Other imaging studies can be useful. Barium enema may show an abnormally positioned or mobile cecum. However, the cecum is normally higher and more medial in the abdomen in the neonate than in older patients [9]. The cecum can also appear to be normally positioned on enema studies, even in some patients with malrotation and midgut volvulus $[6,9]$. Inversion of the superior mesenteric vein and artery is a useful sonographic finding and suggests malrotation. However, inversion is present in only about $60 \%$ of cases of surgically proved malrotation $[10,11]$. We have also encountered inversion of the mesenteric vessels in neonates with duodenal atresia, without malrotation, presumably because of leftward displacement of the superior mesenteric vein by the dilated duodenum. Coexistent obstruction distal to the duodenal atresia should be suspected when ultrasound reveals dilated, fluid-filled loops of jejunum or ileum [9].

Following repair of the duodenal atresia, the radiographic appearance of malrotation can be simulated at UGI by postoperative deformity and displacement of the duodenum. Although this appearance may result from mobilization or actual surgical division of the ligament of Treitz, it is probably more likely to be secondary to deformity of the sweep related to adhesions and traction on the bowel from the resection of the atretic segment and the anastomosis. A similar appearance of the duodenojejunal loop simulating malrotation can also be seen in patients with distal small bowel obstruction, again probably due to traction on the duodeno-jejunal junction [12]. In some patients, the cecum must also be first mobilized to obtain surgical access to the obstructed duodenum. As a result, the cecum may appear abnormally mobile postoperatively.

\section{References}

1. Young DG, Wilkinson AW (1968) Abnormalities associated with neonatal duodenal obstruction. Surgery 63: 832-6

2. Fonkalsrud EW, de Lorimier AA, Hays DM (1969) Congenital atresia and stenosis of the duodenum - a review compiled from the members of the surgical section of the American Academy of Pediatrics. Pediatrics 43: 79-83

3. Reid IS (1973) The pattern of intrinsic duodenal obstructions. Aust NZ J Surg 42: 349-52

4. Salonen IS (1978) Congenital duodenal obstruction. Acta Paediatr Scand [Suppl] 272: 1-86

5. Simpson AJ, Leonidas JC, Krasna IH, Becker JM, et al (1972) Roentgen diagnosis of midgut malrotation: value of upper gastrointestinal radiographic study. J Pediatr Surg 7: 243-252

6. Beasley SW, De Campo JF (1987) Pitfalls in the radiological diagnosis of malrotation. Australas Radiol 31: 376-383

7. Katz ME, Siegel MJ, Shackelford GD, McAlister WH (1987) The position and mobility of the duodenum in children. AJR 148: 947-951 
8. Zerin JM (1992) Contrast studies of the gastrointestinal tract in the neonate. Semin Pediatr Surg 1: 284-295

9. Parker BR (1993) The abdomen and gastrointestinal tract. In: Silverman FN, Kuhn JP (eds) Caffey's pediatric X-ray diagnosis: an integrated approach, 9th edn. Mosby, St Louis, pp 2048-2055
10. Zerin JM, DiPietro MA (1992) Superior mesenteric vascular anatomy at US in patients with surgically proved malrotation of the midgut. Radiology 183: 693-694

11. Dufour D, Delaet MH, Dassonville M, Cadranel S, Perlmutter N (1992) Midgut malrotation, the reliability of sonographic diagnosis. Pediatr Radiol 22: 21-23

12. Taylor GA, Teele RL (1985) Chronic intestinal obstruction mimicking malrotation in children. Pediatr Radiol 15: 392-394

\section{Literature in pediatric radiology}

Airway compromise secondary to vascular compression in a neonate. Terris, M. H. et al. (Div. of Head and Neck Surg., Univ., 225 Dickinson St. 8895, San Diego, CA 92123, USA) 28:193 (1994)

Nasal pyriform aperture stenosis and the holoprosencephaly spectrum. Tavin, E. et al. (Dept. of Otolaryngol., and Dept. of Ped., Center for Congenital Disorders, Montefiore Med. Center, The Bronx, NY, USA) 28: 199 (1994)

Congenital lobar emphysema: a case with bronchial septum. Saim, L. et al. (Dept. of Otolaryngol., Harvard Med. School, Eye and Ear Infirmary, 243 Charles St., Boston, MA USA) 28 : $241(1994)$

\section{Journal of Bone and Joint Surgery, British Volume}

(London)

Spinal deformity after childhood surgery for tuberculosis of the spine. Upadhyay, S. S. et al. (The Duchess of Kent Children's Hosp., 12 Sandy Bay Rd., Sandy Bay, Hong Kong) 76-B: 91 (1994)

Cystic tuberculosis of bone in children. Rasool M.N. et al. (Dept. of Orthop., Univ. of Natal, PO Box 17039, Congella 4013, Durban, Rep. of South Africa) 76-B: 113 (1994)

\section{Annales de Pédiatrie (Paris)}

Retroperitoneal teratomas in the perinatal period. Report of a case of neonatal, immature, aggressive teratoma, with a review of the literature. [In French] Augé, B. et al. (Laboratoire dÁnatomie Pathol., Centre Paul Strauss, 3 rue de la Porte de l'Hôpital, F-67085 Strasbourg cedex, France) 40: 613 (1993)

Hydatid disease of the liver and portal hypertension in pediatric patients. Is the diagnosis BuddChiari syndrome? [In French] Khaldi, F. et al. (Serv. de Méd. Infantile A, Hôpital d'Enfants, Bab Saadoun 1007, Tunis-Jebbari, Tunisie) 40: 631 (1993)

\section{Archives Françaises de Pédiatrie (Paris)}

A rare cause of bone pain in children: primary hyperparathyroidism due to an adenoma. [In French] Kauffmann, C. et al. (Leroy, B., Serv. de Néphrol. Péd., Hôpital Trousseau, 26 av. du Dr. Arnold-Netter, F-75571 Paris cedex 12, France) 50: 771 (1993)

Granulocytic sarcoma and mediastinal mass. [In French] Ouchiha, M. et al. (Ferster, A., Unité d'Hémato-Oncol., Hôpital Univ. des Enfants, av. J.J.-Crocq, 15, B-1020 Bruxelles, Belgium) 50: 775 (1993)

Post-operative chylous effusion after Bochdalek herniorrhaphy in two neonates. [In French] Tilmont, P. et al. (Serv. de Réanimation Néonatale et Infantile, Centre Hosp. Félix-Guyon, F-97400 Saint-Denis (Réunion), France) 50: 783 (1993)
Histiocytose X pulmonaire de l'enfant: forme pseudo-tumorale (cas radiologique du mois). Pilorget, H., Renouil, M. (Serv. de Péd., Centre Hosp. Général Le Tampon, BP 350, F-97448 Saint-Pierre cedex, France) 50:793 (1993)

Une atteinte hépatique multinodulaire révélatrice d'un lymphome malin non hodgkinien (cas radiologique du mois). Souhayl, A. et al. (Ducou Le Pointe, H., Serv, de Rad., Hôptial d'Enfants Armand-Trousseau, 26, av. du Dr.-Arnold-Netter, F-75571 Paris cedex, France) 50: 797 (1993)

Right intraventricular thrombus, a rare complication of caval catheterization. [In French] Doireau, V. et al. (Daoud, P., Unité de Réanimation Méd., Hôpital Saint-Vincent-de-Paul, 82, av. Denfert-Rocherau, F-75674 Paris cedex 14, France) 50: 887 (1993)

Perinatal lethal osteogenesis imperfecta in a Congolese child. [In French] Moyen, G. (CHU, BP 32, Brazzaville, Congo) 50: 891 (1993)

Robinow syndrome with deafness. [In French] Samoud, A. et al. (Serv. de Péd., Hôpital La Rabta, 1007 Tunis, Tunesie) 50: 897 (1993)

Clear cell sarcoma of tendons and aponeuroses. [In French] Drouin, V. et al. (Serv. de Péd. et Génétique Méd., Hôpital Ch.-Nicolle, 1, rue de Germont, F-76031 Rouen cedex, France) 50: 901 (1993)

Kyste hydatique du poumon (cas radiologique du mois). Michaud, L. et al. (Turck, D., Serv. de Péd., Hôpital Huriez, 1, place de Verdun, F59037 Lille cedex, France) 50: 909 (1993)

\section{Journal de Radiologie (Paris)}

Radiological appearances of vertebromedullary hydatidosis. Report of 12 cases. [In French] Chikhaoui, N. et al. (Kadiri, R., CHU Tbn Rochd de Casablanca, Marocco) 74: 621 (1993)

The radiologic aspect of the histiocytosis $X$. [In French] Ouzidane, L. et al. (Serv. de Rad., Hôpital d'Enfants C.H. IBN Rochd, Casablanca, Marocco) 74:629 (1993)

Vascular complications following renal transplantation in children. [In French] Gagnadoux, M.F. et al. (Serv. de Néphrol. Péd., Hôpital des Enfants-Malades, 149-161, rue de Sèvres, F-75015 Paris, France) 75: 57 (1994)

\section{Chirurgische Praxis (München)}

Lungensequester im Kindesalter. Diagnostisches Vorgehen. Meyer, D. et al. (Chirurg. Klinik und Poliklinik der Univ., Josef-Schneider-Str. 2, D97080 Würzburg, FRG) 47: 99 (1993)

Typische Sportverletzungen im Kindesalter. Von Laer, L. (Traumatol. Abt., Kinderklinik, Römergasse 8, CH-4005 Basel, Switzerland) 47:117 (1993)

Die Bedeutung der Farbdopplersonografie beim akuten Skrotum in Kindesalter. Herterich, R. et
Continued from p. 169

al. (Kinderkrankenhaus St.Marien, Grillparzerstr. 9, D-84036 Landshut, FRG) 47: 343 (1993)

Kongenitales lobäres Emphysem der Lunge. Kelm, C. et al. (Klinik für Allgemein- und Thoraxchirurg., Med. Zentrum für Chirurg. der Univ., Klinikstr. 29, D-35392 Gießen, FRG) 47: 359 (1993)

\section{European Journal of Pediatrics (Berlin)}

Disseminated cat-scratch disease: detection of Rochalimaea henselae in affected tissue. Waldvogel, K. et al. (Nadal, D., Div. of Immunol./ Haematol, Univ. Children's Hosp., Steinwiesstr. 75, CH-8032 Zürich, Switzerland) 153: 23 (1994)

\section{European Radiology (Berlin)}

Septo-optic dysplasia associated with total absence of the corpus caliosum: MR and CT features. Sener, R. N. (Rad. Dept., Ege Univ. Hosp., Bornova, TR-35100 Izmir, Turkey) 3:551 (1993)

Aberrant renal papilla: sonographic detection in childhood. Alzen, G., Wildberger, J.E. (Dept. of Rad., Clinical Centre, RWTH, Pauwelsstr. 30, D-52074 Aachen, FRG) 3: 558 (1993)

Fortschritte auf dem Gebiete der Röntgenstrahlen und der neuen bildgebenden Verfahren (Stuttgart) Early experience with a new method for treating intussusceptions: sonographically controlled hydrostatic reduction. [In Germ.] Rohrschneider, W. et al. (Abt. Päd. Rad., Rad. Klinik, Ruprecht-Karls Univ., Im Neuenheimer Feld 153 , D-69120 Heidelberg, FRG) 160:35 (1994)

\section{Klinische Pädiatrie (Stuttgart)}

The infiltrating intramuscular hemangioma. [In Germ.] Günther, K. et al. (Orthop. Klinik der Univ. Orthop. Abt. des Rehabilitationskrankenhauses, D-89075 Ulm, FRG) 206: 59 (1994)

\section{Monatsschrift Kinderheilkunde (Berlin)}

Iliaca vein thrombosis associated with protein $C$ deficiency after infectious mononucleosis. [In Germ.] Knees, U. et al. (Kinderklinik und Kinderpoliklinik, Techn. Univ., Kölner Platz 1, D80804 München, FRG) 141: 928 (1993)

Diagnosis of non-calcifying vasculopathy in the basal ganglia by colour Doppler imaging. [In Germ.] Ries, M., Deeg, K.-H. (Klinik mit Poliklinik für Kinder und Jugendliche, Univ, Loschgestr. 15, D-91054 Erlangen, FRG) 142:29 (1994)

Diabetes insipidus centralis and visual impairment: early symptoms of septo-optic dysplasia. [In Germ.] Rütschle, H. et al. (Kinderklinik St. Anna-Stift, Karolina-Burger-Str. 51, D67065 Ludwigshafen, FRG) 142: 37 (1994) 